\title{
Electrochemical Degradation of Carbamazepine: A Case Study of Quantification of "10, 11 Dihydro-10 Hydroxy Carbamazepine And 10, 11- Epoxycarbamazepine" As The Main By-Products Using LC-TOF/MS.
}

\section{Zainab Haider Mussa}

Universiti Teknologi Malaysia

Fouad Fadhil Al-Qaim ( $\square$ fouad.fadhil@uobabylon.edu.iq )

University of Babylon

\section{Research Article}

Keywords: 10,11-dihydro10-hydroxy carbamazepine, 10,11-epoxycarbamazepine, electrochemical oxidation process, solid phase extraction, LC-TOF/MS, Quantification of by-products

Posted Date: December 20th, 2021

DOI: https://doi.org/10.21203/rs.3.rs-1118086/v1

License: (c) (i) This work is licensed under a Creative Commons Attribution 4.0 International License. Read Full License 


\section{Abstract}

Carbamazepine (CBZ) is one of the most widely used antiepileptic drugs in Malaysia, so, it was detected in wastewater frequently. The electrochemical treatment process has been applied for the degradation of CBZ using graphite-PVC as an anode. However, two main by-products, namely, 10,11-dihydro10-hydroxy carbamazepine (HDX-CBZ) and 10,11-epoxycarbamazepine (EPX-CBZ) have been analysed and quantified using liquid chromatography-time of flight/mass spectrometry (LC-TOF/MS). HDX-CBZ and EPX-CBZ were analysed in positive ionisation mode and were separated chromatographically using 5 $\mathrm{mm}, 2 \mathrm{~mm}$ ' $150 \mathrm{~mm}$ C18 column at a flow rate of $0.3 \mathrm{~mL} / \mathrm{min}$. To improve sensitivity and detectability, SPE was applied as a pre-concentration step for the treated carbamazepine samples to extract and preconcentrate HDX-CBZ and EPX-CBZ. However, three different solvents, namely, methyl tertiary butyl ether, acetone and methanol, have been optimized to enhance the recovery. The recovery was $85 \%$ and $92 \%$ for HDX-CBZ and EPX-CBZ, respectively, in the presence of methanol. The limit of quantification (LOQ) was 0.588 and $0.109 \mu \mathrm{g} / \mathrm{L}$ for both by-products, respectively. The concentration of HDX-CBZ and EPX-CBZ was 343 and $144 \mu \mathrm{g} / \mathrm{L}$, respectively, after $20 \mathrm{~min}$ of treatment, then, it was decreased to 17.2 and 9.8 $\mu \mathrm{g} / \mathrm{L}$ at $40 \mathrm{~min}$. Finally, both by-products were eliminated after $60 \mathrm{~min}$.

\section{Introduction}

The emergence and fate of pharmaceuticals in the aquatic environment of Malaysia have become a major concern. These compounds have been frequently found in water bodies as well as in reused water, such as sewage wastewater and hospital effluent. Frequent detection can be associated with improper disposal at conventional wastewater treatment plants (Al-Odaini et. 2010; Al-Qaim et al. 2017; Na et al. 2019; Zhang et al. 2020; Quesada et al. 2019). Due to their low concentrations in the environment, these pharmaceuticals can have adverse effects on organisms and humans due to prolonged exposure (Feng et al. 2013; Nikolaou et al. 2017; Zhang et al. 2008). According to the information reported by the Ministry of Health (MOH 9), carbamazepine is one of the most widely used drugs in Malaysia.

Carbamazepine $\left(\mathrm{C}_{15} \mathrm{H}_{12} \mathrm{~N}_{2} \mathrm{O}\right)$ is a pharmaceutical that showed high efficiency in the treatment of partial seizures, tonic-clonic seizures, pain of neurologic origin, such as trigeminal neuralgia and psychiatric disorders, including manic-depressive illness and aggression due to dementia (DrugBank).

Carbamazepine was detected, not only in Malaysia, but it was also frequently detected in surface water and effluent of sewage treatment plants worldwide (Sossalla et al. 2021; Pereira et al. 2021; Hai et al. 2018; Ekpeghere et al. 2018; Perkons et al. 2021). It was reported that the by-products after electrochemical degradation of carbamazepine also have ecotoxicity in fish eggs with $96 \mathrm{~h}$ (Zhu et al. 2020).

Al-Qaim et al. (2018) reported the removal of carbamazepine using the electrochemical process in the application of graphite-PVC anode. In the present study, quantification and treatment of the main byproducts, namely HDX-CBZ and EPX-CBZ, after electrochemical degradation of carbamazepine has not been reported yet. 
Compared to other chemical-oxidation treatment methods or biological treatment processes (Zhang et al. 2020; Zou et al. 2020; Li et al. 2021), electrochemical processes are preferred for many reasons: (i) high efficiency in removing contaminants from very complex matrices, as reported in a previous study (Mussa et al. 2015), (ii) it could be applied at normal conditions in terms of temperature and pressure so no more volatilization process occurred and also no sludge formation, (iii) the reaction itself can only be stopped when there is a lack of power and can be quickly recovered once the interoperability issue is resolved, (iv) it could be safe to the environment as the reagent is "electron", and (v) electrochemical process does not require more chemical reagents.

The anodic-electrochemical oxidation process is simply based on realising the electron to the solution followed by the formation of $\mathrm{Cl}_{2} / \mathrm{H}_{2} \mathrm{O}$ as the main oxidising agent. However, it could be classified into the direct and indirect oxidation process on the surface of the anode and/or at the bulk solution (Moreira et al. 2017). The big challenge in the degradation of pollutants is "what are the by-products after degradation and how to identify and quantify these unknown compounds?" The transformation products are varied, depending on the conditions of the experiment, type of electrolyte and so on. It was reported that after electrochemical degradation of carbamazepine in the presence of chlorine, the by-products could be more toxic with the treatment time and the acute toxicity increased with time (García-Espinoza et al. 2018).

The present study aims to (i) identify and elucidate HDX-CBZ and EPX-CBZ as main by-products after electrochemical degradation of carbamazepine, (ii) quantify the concentration of HDX-CBZ and EPX-CBZ as main by-products using LC-TOF/MS, (iii) investigate the fate of HDX-CBZ and EPX-CBZ as main byproducts after electrochemical degradation of carbamazepine within $60 \mathrm{~min}$ of the electrochemical process using LC-TOF/MS.

\section{Experimental Part}

\section{Reagents}

All standards are pure with $\geq 98 \%$ of carbamazepine (CAS no. 298-46-4), 10,11-dihydro-10-hydroxy carbamazepine (CAS no. 29331-92-8) and 10,11-epoxycarbamazepine (CAS no. 61-68-7) were purchased from Sigma-Aldrich (USA). De-ionized water used was supplied by EASYPure RODI (USA). Oasis HLB (3cc, Waters, USA) cartridges were used in all solid phase extraction experiments. Formic acid (FA), methanol $(\mathrm{MeOH})$, acetonitrile (ACN) and acetone were all HPLC-grade and they were supplied by Merck (Germany). Methyl tertiary butyl ether (MTBE) and ethyl acetate were supplied by Baker (USA).

Individual 0.01 gram of standard compounds were dissolved in $10 \mathrm{~mL}$ of methanol to prepare (1000 $\mathrm{mg} / \mathrm{L}$ ) and was stored at $\left.-18{ }^{\circ} \mathrm{C}\right)$. Equal volumes of individual stock solutions were mixed and diluted in $\mathrm{MeOH}-\mathrm{DIW}(1: 9, \mathrm{v} / \mathrm{v})$ before being injected into LC-TOF/MS.

\section{Electrochemical cell setting}


Carbamazepine has been degraded using $100 \mathrm{~mL}$-cell consists of the cathode, a platinum sheet of $1.5 \times$ $1.5 \mathrm{~cm}$ dimensions. The opposite electrode was graphite-PVC anode as a pellet ( $20 \mathrm{~mm}$ diameter). However, both anode and cathode electrodes were connected to the DC power supply (CPX200 DUAL, 35 V 10 A PSU, Thurl, Ltd, St. Ives Cambridgeshire, England).

It was electrochemically treated for $20 \mathrm{~min}$ in the presence of a fixed amount of $0.5 \mathrm{~g} \mathrm{NaCl}$ and 5 volt. Then, the solutions were filtered and extracted before being injected into LC-TOF/MS.

\section{Extraction of the by-products}

For sensitive and accurate by-product identification, a solid-phase extraction procedure was applied for $100 \mathrm{ml}$ of the treated sample. Before using SPE cartridges, the samples were filtered to exclude any particular matter. HLB cartridges were preconditioned by methanol and water in $2 \mathrm{~mL}$. After that, all filtered samples were passed through the HLB cartridges using a 10-sample vacuum manifold at 3 $\mathrm{ml} / \mathrm{min}$ under vacuum. The drying process was applied for $5 \mathrm{~min}$ at $15 \mathrm{~mL} / \mathrm{min}$ for the cartridges to remove any expected residual water. Then, the by-products were eluted by dispersing $5 \mathrm{ml}$ of methanol, then, evaporated to dry in a gas stream of $\mathrm{N}_{2} .1 .0 \mathrm{ml}$ of $\mathrm{MeOH}$ - DIW (10): 90, v / v) reconstituted the residual by-products. Then, $30 \mu$ of the extract was injected into the LC - TOF / MS instrument for analysis.

\section{Chemical analysis}

The treated solution was separated on Gemini column 5 Nm NX $110 \AA$ C18 (2 mm × 150 mm, Phenomenex) by Dionex Ultimate 3000 / LC 09115047 system (Sunnyvale, CA, USA) equipped with a vacuum degasser, pump quaternary and autosampler. Data were collected by Brucker DataAnalysis software (Fahrenheitstr.4, Bremen, Germany). Positive ionization mode was selected for the identification of carbamazepine and the main by-products HDX-CBZ and EPX-CBZ. Details of the gradient program and mobile phases were shown in Table 1. The molecular ions of by-products were detected as $[\mathrm{M}+\mathrm{H}]^{+}$and $[\mathrm{M}+\mathrm{Na}]^{+}$.

Table 1

Chromatographic separation of CBZ and its by-products HDX-CBZ and EPX-CBZ

\begin{tabular}{|c|c|c|c|c|c|c|c|}
\hline \multicolumn{8}{|l|}{ Positive lon } \\
\hline \multirow[t]{2}{*}{ Mobile Phase } & \multicolumn{7}{|c|}{$A: 0.1 \%$ FA in DIW } \\
\hline & \multicolumn{7}{|c|}{ B: ACN-MeOH $(3: 1, v / v)$} \\
\hline Flow Rate & \multicolumn{7}{|l|}{$0.3 \mathrm{~mL} / \mathrm{min}$} \\
\hline Injection Volume & \multicolumn{7}{|l|}{$30 \mu \mathrm{L}$} \\
\hline \multirow[t]{2}{*}{ Gradient Program } & Time (min) & 0 & 3 & 6 & 11 & 11.1 & 16.1 \\
\hline & $B \%$ & $5 \%$ & $60 \%$ & $97 \%$ & $97 \%$ & $5 \%$ & $5 \%$ \\
\hline
\end{tabular}




\section{Quantification and method validation}

After reconstitution of the by-products, they were extracted accurately using a very narrow window " 0.02 $\mathrm{Da}$ " in LC-TOF/MS instrument. The identification and confirmation of the by-products in the treated samples were based on two factors:

(a) the exact value of the mass to charge ratio $(\mathrm{m} / \mathrm{z})$ of the main molecular ion and (b) the retained time (Rt) for the target by-product. The instrumental limit of quantification (IQL) was assessed by successive injections of the diluted standard solution until it reached a concentration level equal to an $\mathrm{s} / \mathrm{n}$ ratio of $\geq 10$. Calibration curves were generated for each by-product by matching the respective peak area with the concentrations of each analyte using a linear regression model. Linearity was good, in which the correlation coefficient $\left(R^{2}\right)$ was $\left.>0.993\right)$. The LOQ quantification limit $(\mu \mathrm{g} / \mathrm{L})$ for all methods was calculated using the following equation (Vieno et al. 2006):

$\mathrm{LOQ}=\frac{\mathrm{IQL} \times 100}{\mathrm{R} \% \times \mathrm{CF}}$

Where IQL is the instrumental quantification limit $(\mu \mathrm{g} / \mathrm{L}), \mathrm{R}(\%)$ is the recovery of the by-product in the sample matrix at the concentration level of IQL, and CF is the concentration factor (100).

To determine the recovery, five replicates were performed at spiking levels of 50 and $10 \mu \mathrm{g} / \mathrm{L}$ for HDX-CBZ and EPX-CBZ, respectively. The recoveries were evaluated by comparing the solid phase extracted samples to non-extracted standard solutions as presented below:

$\mathrm{R} \%=\frac{\mathrm{A}_{\mathrm{SP}}}{\mathrm{A}_{\mathrm{S}}} \times 100 \%$

Where $A_{S P}$ is the peak area of the analyte in the solid-phase extracted sample and $A_{S}$ is the peak area in the solvent-based standard solution.

\section{Results And Discussion}

HDX-CBZ and EPX-CBZ by-products were selected based on their appearance as the main products after electrochemical degradation of carbamazepine. The separation profile for both by-products was presented in (Figure 1). The intensity of the peak area is not the same for both products and varied strongly. Therefore, this variation may be due to the diversity of physicochemical properties under electrospray ionization conditions.

Many solvents have been applied to reconstitute of analytes after solid phase extraction and before injection to LC-TOF/MS. However, pure MeOH (Hernando et al. 2004), 25\% MeOH in water (Gros et al. 2006) and $0.1 \%$ acetic acid in water plus $\mathrm{MeOH}$, were used to reconstitute the residues of pharmaceuticals after SPE (Vieno et al. 2006) 27]. In the present study, MeOH-water (1:90) was used to reconstitute the residual of HDX-CBZ and EPX-CBZ after SPE. 


\section{ToF screening and confirmation}

Liquid chromatography/time-of-flight/mass spectrometry is a developing technique involving the application of the electrospray ionization method to enhance the detection method. Furthermore, a sharp and nice peak exhibited good chromatographic separation in terms of sensitivity and selectivity for the quantification of target compounds in the samples. However, the by-products were analyzed in positive ionization mode $(\mathrm{PI})$ because it exhibited a high signal-to-noise ratio for both by-products. The quantification and monitoring in treated samples were also considered in the PI mode. For enhancing the sensitivity of detecting trace levels of the pharmaceuticals using LC-TOF/MS, a very narrow range window of 0.02 Da has been applied to extract a target peak. It was observed that reducing the mass window plays an important role to increase the detection limit and avoiding any interferences from other organic compounds.

TOF/MS compartment has been applied for confirmation and quantification of the protonated molecular ion of an organic compound. This analysis was investigated by the elemental formula and mass errors, which has been achieved using the software of "Brucker Daltons Data Analysis program". An example of EPX-CBZ has been presented in Figure 2.

However, the elemental formula of EPX-CBZ $\left(\mathrm{C}_{15} \mathrm{H}_{12} \mathrm{~N}_{2} \mathrm{NaO}_{2}\right)$ as sodium adduct molecular ion has a mass error of $-2.9 \mathrm{ppm}$. In addition, some characteristics are shown in Table 2, including the mass measurement, retention time, mass error and elemental composition.

Table 2 Accurate mass measurements obtained by LC-TOF/MS for both by-products (HDX-CBZ and EPXCBZ) after electrochemical oxidation treatment of carbamazepine 


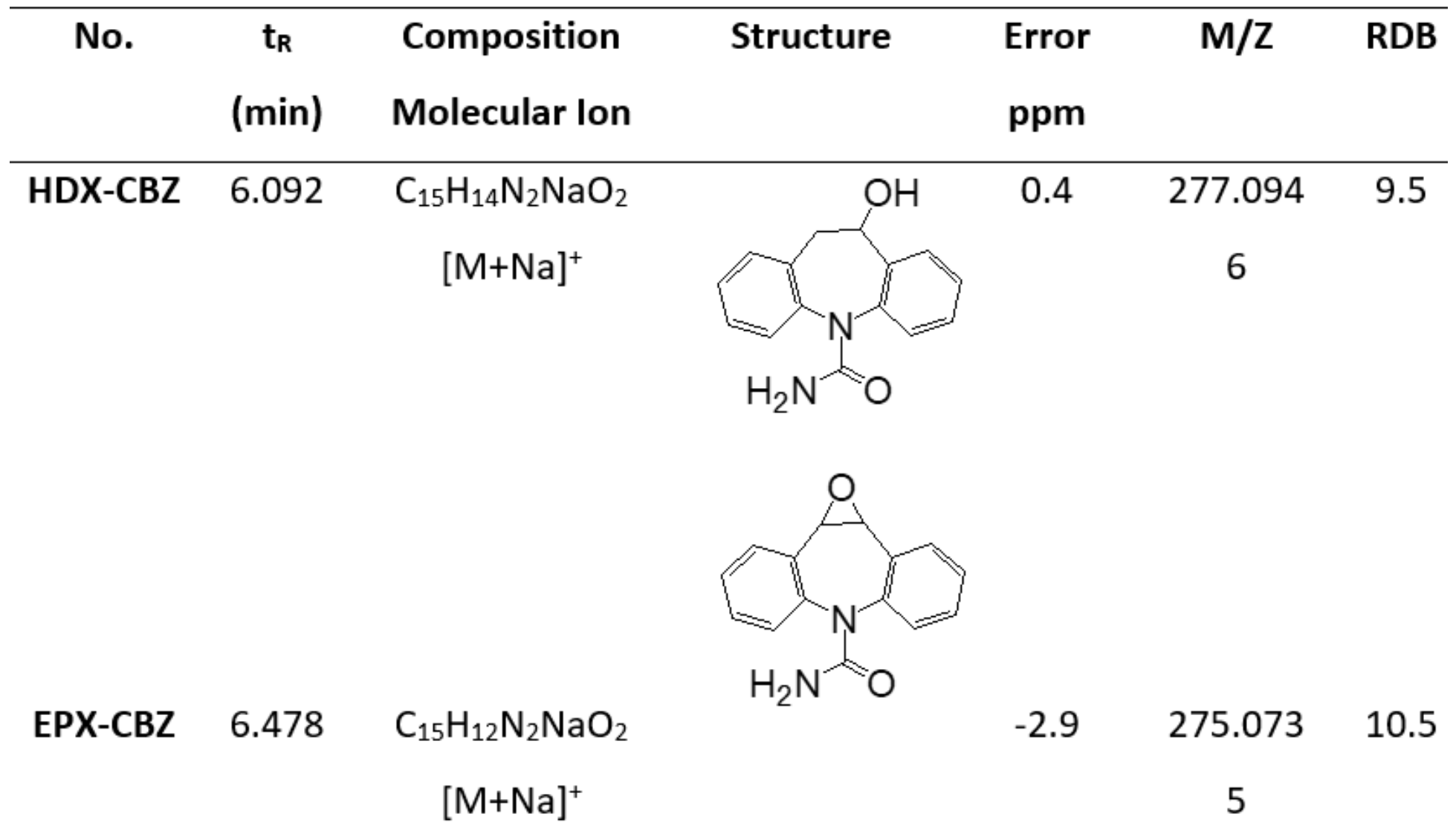

\section{Method validation}

An external calibration curve has been built to exhibit the linearity represented by the correlation coefficient $\left(R^{2}\right)$. A wide range of concentrations ranged between 50 and $1000 \mu \mathrm{g} / \mathrm{L}$ for HDX-CBZ while it was ranged between 10 and $1000 \mu \mathrm{g} / \mathrm{L}$ for EPX-CBZ (Table 3 and Figure 3 ). Good linearity $\left(R^{2} \geq 0.993\right.$ ) was observed. For the calculation of instrumental quantification limit (IQL), the lowest concentration has been injected directly to the LC-ToF/MS, achieving a signal-to-noise ratio (S/N) of 10. HDX-CBZ and EPXCBZ have IQL of 50 and $10 \mu \mathrm{g} / \mathrm{L}$, respectively. The limit of quantification (LOQ) for the applied method was calculated using equation (1). They were 0.588 and $0.109 \mu \mathrm{g} / \mathrm{L}$ for HDX-CBZ and EPX-CBZ, respectively. Compared to the reported study by (Teixeira et al. 2013), the limits of quantification ranged between 25.9 and $39.0 \mu \mathrm{g} / \mathrm{L}$, which is higher than the LOQs reported in the present study. The reason is related to the type of instrument used for method validation. However, LC-TOF/MS exhibited high sensitivity compared to the cyclic voltammetry method.

Table 3

method validation for both by-products (HDX-CBZ and EPX-CBZ)

\begin{tabular}{|llllll|}
\hline Compound & Range conc. $(\mu \mathrm{g} / \mathrm{L})$ & Equation & IQL $(\mu \mathrm{g} / \mathrm{L})$ & $\mathrm{LOQ}(\mu \mathrm{g} / \mathrm{L})$ & Recovery\% \\
\hline HDX-CBZ & $50-1000$ & $\mathrm{y}=67.47 x+3692$ & 50 & 0.588 & 85 \\
\hline EPX-CBZ & $10-1000$ & $\mathrm{y}=481.5 x-4453$ & 10 & 0.109 & 92 \\
\hline * Recovery has been calculated for IQL values. & & & \\
\hline
\end{tabular}


Three concentrations (50, 100 and $200 \mu \mathrm{g} / \mathrm{L}$ ) have been tested to investigate the inter-day repeatability and intra-day reproducibility in three replications. Accepted results have been obtained, in which the RSD $\% \leq 6.7 \%$ for intra-day precision and $11.7 \%$ for inter-day precision as presented in Table 4 . Accuracy was also considered in the present study, in which the recovery was good for both compounds through the SPE method.

Table 4

Intra-day precision and inter-day precision for both by-products (HDX-CBZ and EPX-CBZ)

\begin{tabular}{|lllllll|}
\hline By-product & \multicolumn{3}{l}{ Intra-day precision (mean \pm SD), $\mathrm{n}=\mathbf{3}$} & \multicolumn{3}{l|}{ Inter-day precision (mean. $\mathbf{S D}$ ), $\mathrm{n}=\mathbf{3}$} \\
\cline { 2 - 7 } & $\mathbf{5 0} \boldsymbol{\mu g} / \mathrm{L}$ & $\mathbf{1 0 0} \boldsymbol{\mu g} / \mathrm{L}$ & $\mathbf{2 0 0} \boldsymbol{\mu g} / \mathrm{L}$ & $\mathbf{5 0} \boldsymbol{\mu g} / \mathrm{L}$ & $\mathbf{1 0 0} \boldsymbol{\mu g} / \mathrm{L}$ & $\mathbf{2 0 0} \boldsymbol{\mu g} / \mathrm{L}$ \\
\hline HDX-CBZ & $50.7 \pm 1.53$ & $99.3 \pm 2.52$ & $201.7 \pm 2.08$ & $51.0 \pm 2.65$ & $98.7 \pm 3.79$ & $202.7 \pm 3.21$ \\
\hline EPX-CBZ & $48.7 \pm 0.58$ & $98.3 \pm 1.15$ & $200.7 \pm 3.05$ & $49.3 \pm 2.52$ & $98.0 \pm 2.65$ & $201.7 \pm 3.25$ \\
\hline
\end{tabular}

\section{Effect of elution solvent}

Three solvents have been examined to achieve the best recovery for both by-products. However, methyl tertiary butyl ether (MTBE), acetone and methanol were investigated separately. The lowest recovery was observed with MTBE $(5 \times 1 \mathrm{~mL})$ while the best recovery was achieved with methanol $(5 \times 1 \mathrm{~mL})$.

Both by-products were prepared in the concentration of IQL value for each one, then, subjected to SPE method after that eluted with $5 \mathrm{~mL}$ of solvent. The by-products HDX-CBZ and EPX-CBZ exhibited the highest recovery of $85 \%$ and $92 \%$, respectively with methanol as eluent. However, low recoveries were observed with MTBA and acetone solvents compared to methanol. It could be concluded that methanol, a polar solvent, compared to other solvents, resulted in increased recovery of both by-products. Finally, methanol has been selected as the best eluent for both by-products as presented in Figure 4 .

\section{Identification of EDX-CBZ and HDX-CBZ by-products}

Carbamazepine has been degraded electrochemically using different electrodes and different purposes as reported previously (García-Espinoza et al. 2018; Teixeira et al. 2013; Xu et al. 2021). The identification and quantification of the main by-products after electrochemical degradation of carbamazepine is necessary to study their fate using LC-TOF/MS before discharge to water bodies.

It is well known that in the electrochemical degradation process, a low concentration of by-products could be produced. However, the identification and quantification required an accurate and sensitive instrument, such as LC-TOF/MS.

Two main by-products (HDX-CBZ: $6.092 \mathrm{~min}$ and EPX-CBZ: $6.478 \mathrm{~min}$ ) were generated during the electrochemical degradation of CBZ. It was reported that HDX-CBZ and EPX-CBZ have been formed as 
main by-products after electrochemical degradation of carbamazepine using novel blue-colored $\mathrm{TiO}_{2}$ nanotubes anode. The previous study was focusing on the qualitative analysis, not quantification since no standard for both by-products was calibrated and both by-products were detected as protonated molecular ions $[\mathrm{M}+\mathrm{H}]^{+}$(Xu et al. 2021). Figure 5 shows the mass fragmentation chromatogram of both by-products, HDX-CBZ and EPX-CBZ as sodium adduct molecular ion $\left([\mathrm{M}+\mathrm{Na}]^{+}\right.$. High $\mathrm{S} / \mathrm{N}$ ratio was obtained for both by-products due to the pre-concentration sample using solid phase extraction protocol ( $3 \mathrm{cc} \mathrm{HLB}$ cartridges) and also to the optimal choice for the mobile phase and elution program as explained in sections 3.2 and 3.3. A very narrow window of " $0.02 \mathrm{Da}$ " has been applied for the extraction of chromatographic peaks using the Bruker Daltonic Analysis software.

\section{Monitoring the by-products after degradation process}

It is well known that after the degradation of carbamazepine, the compound itself could be reduced with time due to the degradation process. The treated sample of carbamazepine has been retained and separated on a Gemini $5 \mu \mathrm{m}$ NX $110 \AA$ C18 column $(2 \mathrm{~mm} \times 150 \mathrm{~mm}$, Phenomenex) using liquid chromatography-time of flight/mass spectrometry. Carbamazepine chromatograms profile as extracted ion chromatogram (EIC) after $0,20,40$ and 60 min of the electrochemical treatment process are well presented in Figure 6.

The efficiency of the electrochemical process has been evaluated by monitoring the by-products for 60 min. After 20 min of the electrochemical degradation process, two main by-products HDX-CBZ and EPXCBZ were detected and analyzed using LC-TOF/MS at retention times of 6.092 and $6.478 \mathrm{~min}$, respectively. The main HDX-CBZ and EPX-CBZ by-products were quantified based on the linear regression equation as mentioned previously. Both by-products HDX-CBZ and EPX-CBZ were formed at the maximum concentrations of 343 and $144 \mu \mathrm{g} / \mathrm{L}$, respectively at 20 min of the electrochemical treatment, then, they were decreased to 17.2 and $9.8 \mu \mathrm{g} / \mathrm{L}$, respectively at $40 \mathrm{~min}$ as shown in Figure 7. This behavior was in agreement with a previous study reported by (Xu et al. 2021). He noticed that at the first 20 min, the maximum yield of the by-products was achieved. After that, all by-products disappeared within 80 min.

\section{Conclusions}

An analytical method using liquid chromatography time of flight mass spectrometry was developed and validated for the identification and quantification of HDX-CBZ and EPX-CBZ as main by-products after electrochemical degradation of CBZ. Buying standard products helps in the quantification and identification of these by-products in treated samples as well as applying solid-phase extraction to reconstitute them. Recovery was $85 \%$ and $92 \%$ for HDX-CBZ and EPX-CBZ, however, the limit of quantification for both by-products was 0.588 and $0.109 \mu \mathrm{g} / \mathrm{L}$, respectively. Furthermore, the fate of the by-products was investigated after monitoring the by-products for $60 \mathrm{~min}$ of electrochemical degradation of carbamazepine. It was observed that the maximum amount has been formed at $20 \mathrm{~min}$, then, reduced 
with time until it disappeared. HDX-CBZ and EPX-CBZ were formed at concentrations of 343.6 and 144 $\mu \mathrm{g} / \mathrm{L}$, respectively at $20 \mathrm{~min}$ of electrochemical degradation of carbamazepine.

\section{Declarations}

Authors Contributions: Zainab Haider Mussa: lab work, methodology, data collection, electrochemical cell construction.

Fouad Fadhil Al-Qaim: methodology, validation, writing (original draft), writing (editing), elucidation the by-products.

Ethics approval and consent to participate Not applicable.

Consent for publication Not applicable.

Competing interests The authors declare no competing interests

Funding Not applicable

Availability of data and materials Not applicable

Acknowledgments Support for this study was provided by Central Research Instrumentation of Management, Universiti Kebangsaan Malaysia. The authors would like to thank all staff in the centre.

\section{References}

1. Al-Odaini NA, Zakaria MP, Yaziz MI, Surif S (2010) Multi-residue analytical method for human pharmaceuticals and synthetic hormones in river water and sewage effluents by solid-phase extraction and liquid chromatography-tandem mass spectrometry. J Chromatogr A 1217(44):67916806

2. Al-Qaim FF, Jusof SH, Abdullah MP, Mussa ZH, Tahrim NA, Khalik W, Othman MR (2017) Determination of caffeine in surface water using solid phase extraction and high performance liquid chromatography. Malay J Anal Sci 21(1):95-104

3. DrugBank : https://www.drugbank.ca/drugs/DB00784.Accessed at 09 August 2020

4. Ekpeghere KI, Sim WJ, Lee HJ, Oh JE (2018) Occurrence and distribution of carbamazepine, nicotine, estrogenic compounds, and their transformation products in wastewater from various treatment plants and the aquatic environment. Sci Total Environ 640:1015-1023

5. Feng L, Van Hullebusch ED, Rodrigo MA, Esposito G, Oturan MA (2013) Removal of residual antiinflammatory and analgesic pharmaceuticals from aqueous systems by electrochemical advanced oxidation processes. A review. Chem Eng J 228:944-964

6. García-Espinoza JD, Mijaylova-Nacheva P, Avilés-Flores M (2018) Electrochemical carbamazepine degradation: effect of the generated active chlorine, transformation pathways and toxicity. 
Chemosphere 192:142-151

7. Gros M, Petrović M, Barceló D (2006) Development of a multi-residue analytical methodology based on liquid chromatography-tandem mass spectrometry (LC-MS/MS) for screening and trace level determination of pharmaceuticals in surface and wastewaters. Talanta 70(4):678-690

8. Hai FI, Yang S, Asif MB, Sencadas V, Shawkat S, Sanderson-Smith M, Yamamoto K (2018) Carbamazepine as a possible anthropogenic marker in water: occurrences, toxicological effects, regulations and removal by wastewater treatment technologies. Water 10(2):107

9. Hernando MD, Petrovic M, Fernández-Alba AR, Barceló D (2004) Analysis by liquid chromatographyelectrospray ionization tandem mass spectrometry and acute toxicity evaluation for $\beta$-blockers and lipid-regulating agents in wastewater samples. J Chromatogr A 1046(1-2):133-140

10. Li Y, Yang Y, Lei J, Liu W, Tong M, Liang J (2021) The degradation pathways of carbamazepine in advanced oxidation process: a mini review coupled with DFT calculation. Sci Total Environ 779:146498

11. Malaysian Statistics on Medicine, Ministry of Health Malaysia, Kuala Lumpur, Malaysiahttp://apps.who.int/medicinedocs/documents/s17580en/s17580en.pdf. Accessed 11 December 2020

12. Moreira FC, Boaventura RA, Brillas E, Vilar VJ (2017) Electrochemical advanced oxidation processes: a review on their application to synthetic and real wastewaters. Appl Catal B-Environ 202:217-261

13. Mussa ZH, Othman MR, Abdullah MP (2015) Electrochemical oxidation of landfill leachate: investigation of operational parameters and kinetics using graphite-PVC composite electrode as anode. J Brazil Chem Soc 26:939-948

14. Na TW, Kang TW, Lee KH, Hwang SH, Jung HJ, Kim K (2019) Distribution and ecological risk of pharmaceuticals in surface water of the Yeongsan river, Republic of Korea. Ecotox Environ Safe 181:180-186

15. Nikolaou A, Meric S, Fatta D (2007) Occurrence patterns of pharmaceuticals in water and wastewater environments. Anal Bioanal Chem 387:1225-1234

16. Pereira D, Rocha LS, Gil MV, Otero M, Silva NJ, Esteves VI, Calisto V (2021) In situ functionalization of a cellulosic-based activated carbon with magnetic iron oxides for the removal of carbamazepine from wastewater. Environ Sci Poll Res 28:18314-18327

17. Perkons I, Rusko J, Zacs D, Bartkevics V (2021) Rapid determination of pharmaceuticals in wastewater by direct infusion HRMS using target and suspect screening analysis. Sci Total Environ 755:142688

18. Quesada HB, Baptista ATA, Cusioli LF, Seibert D, de Oliveira Bezerra C, Bergamasco R (2019) Surface water pollution by pharmaceuticals and an alternative of removal by low-cost adsorbents: A review. Chemosphere 222:766-780

19. Sossalla NA, Nivala J, Reemtsma T, Schlichting R, König M, Forquet N, Escher BI (2021) Removal of micropollutants and biological effects by conventional and intensified constructed wetlands treating municipal wastewater. Water Res 201:117349 
20. Teixeira JG, Veiga A, Carvalho AJP, Teixeira DM (2013) Electro-oxidation of carbamazepine metabolites: characterization and influence in the voltammetric determination of the parent drug. Electrochim Acta 108:51-65

21. Vieno NM, Tuhkanen T, Kronberg L (2006) Analysis of neutral and basic pharmaceuticals in sewage treatment plants and in recipient rivers using solid phase extraction and liquid chromatographytandem mass spectrometry detection. J Chromatogr A 1134(1-2):101-111

22. Xu L, Niu J, Xie H, Ma X, Zhu Y, Crittenden J (2021) Effective degradation of aqueous carbamazepine on a novel blue-colored $\mathrm{TiO}_{2}$ nanotube arrays membrane filter anode. J Hazard Mater 402:123530

23. Zhang Y, Duan L, Wang B, Liu CS, Jia Y, Zhai N, Yu G (2020) Efficient multiresidue determination method for 168 pharmaceuticals and metabolites: optimization and application to raw wastewater, wastewater effluent, and surface water in Beijing, China. Environ Poll 261:114113

24. Zhang Y, Geißen S-U, Gal C (2008) Carbamazepine and diclofenac: removal in wastewater treatment plants and occurrence in water bodies. Chemosphere 73(8):1151-1161

25. Zhang Z, Chen H, Wang J, Zhang Y (2020) Degradation of carbamazepine by combined radiation and persulfate oxidation process. Radiat Phys Chem 170:108639

26. Zhu L, Santiago-Schübel B, Xiao H, Thiele B, Zhu Z, Qiu Y, Küppers S (2015) An efficient laboratory workflow for environmental risk assessment of organic chemicals. Chemosphere 131:34-40

27. Zou R, Tang K, Angelidaki I, Andersen HR, Zhang Y (2020) An innovative microbial electrochemical ultraviolet photolysis cell (MEUC) for efficient degradation of carbamazepine. Water Res 187:116451

28. Zou R, Tang K, Angelidaki I, Andersen HR, Zhang Y (2020) An innovative microbial electrochemical ultraviolet photolysis cell (MEUC) for efficient degradation of carbamazepine. Water Res 187:116451

\section{Figures}




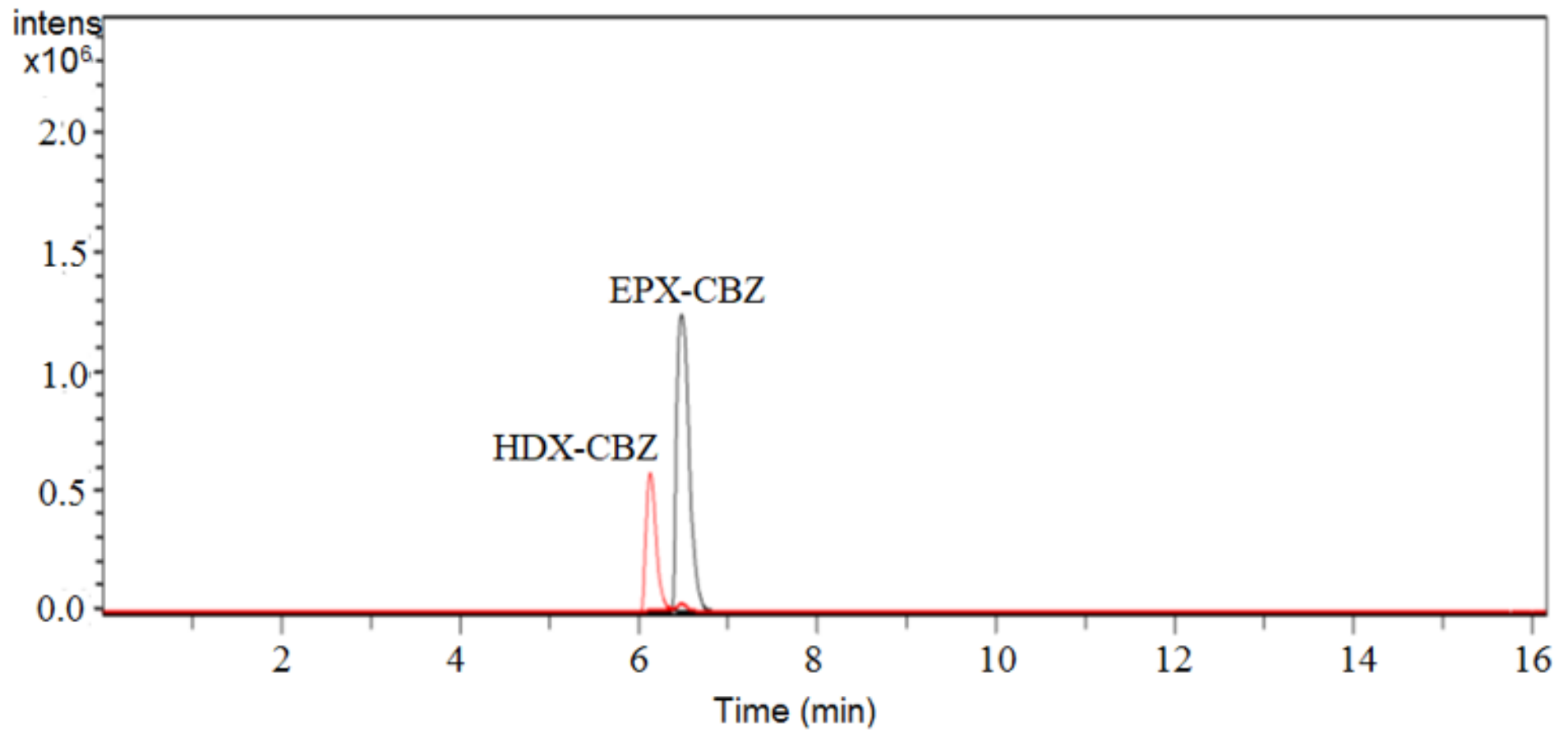

Figure 1

LC-TOF/MS chromatogram for HDX-CBZ and EPX-CBZ by-products.

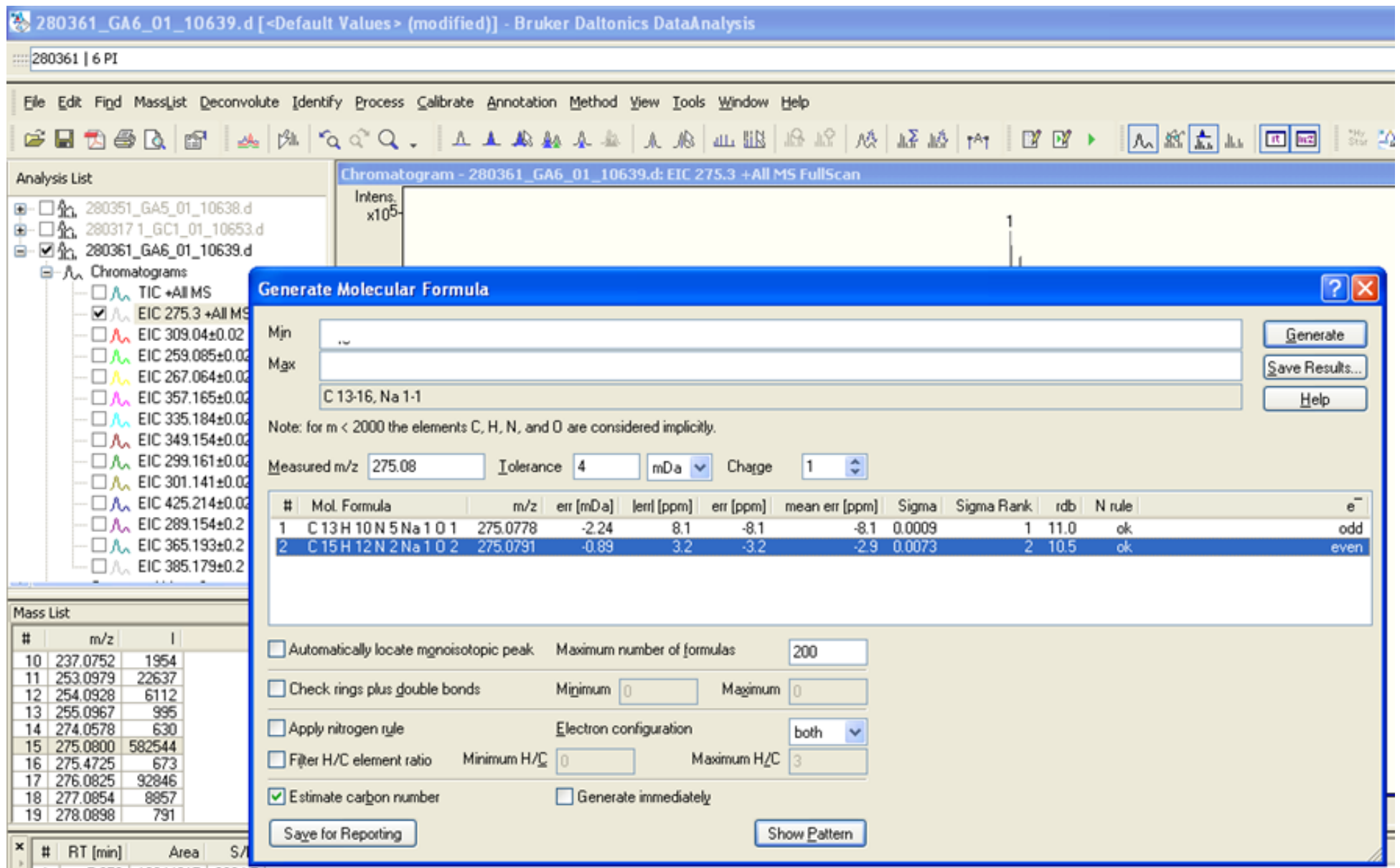

Figure 2 
Example of the application Bruker Daltonics DataAnalysis software: the analysis of EPX-CBZ by-product.
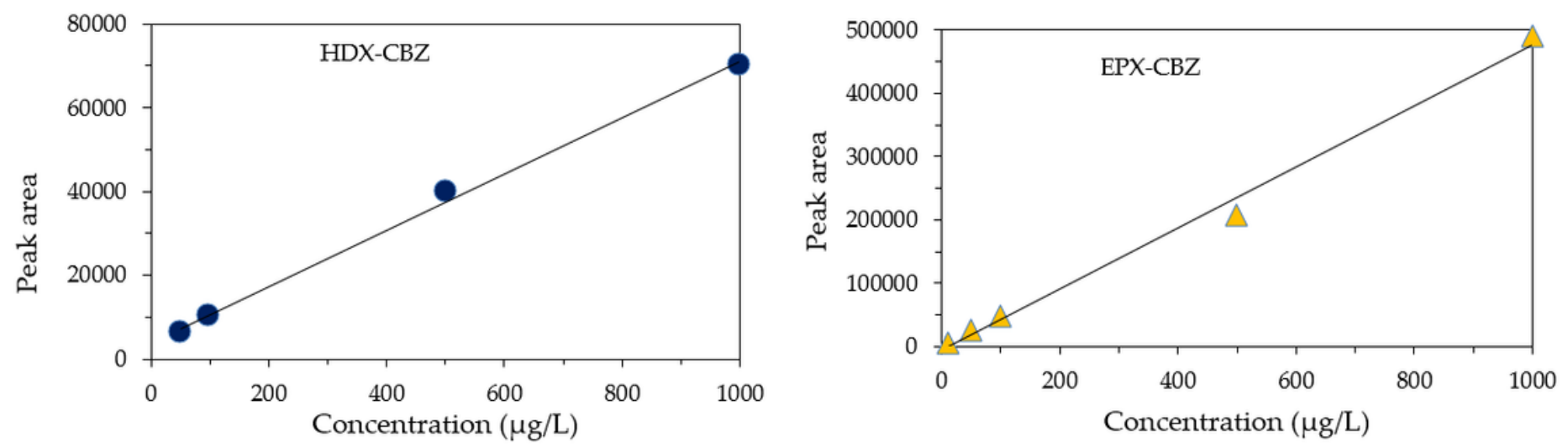

Figure 3

Calibration curve profile for the by-products: (top) HDX-CBZ and (bottom) EPX-CBZ.

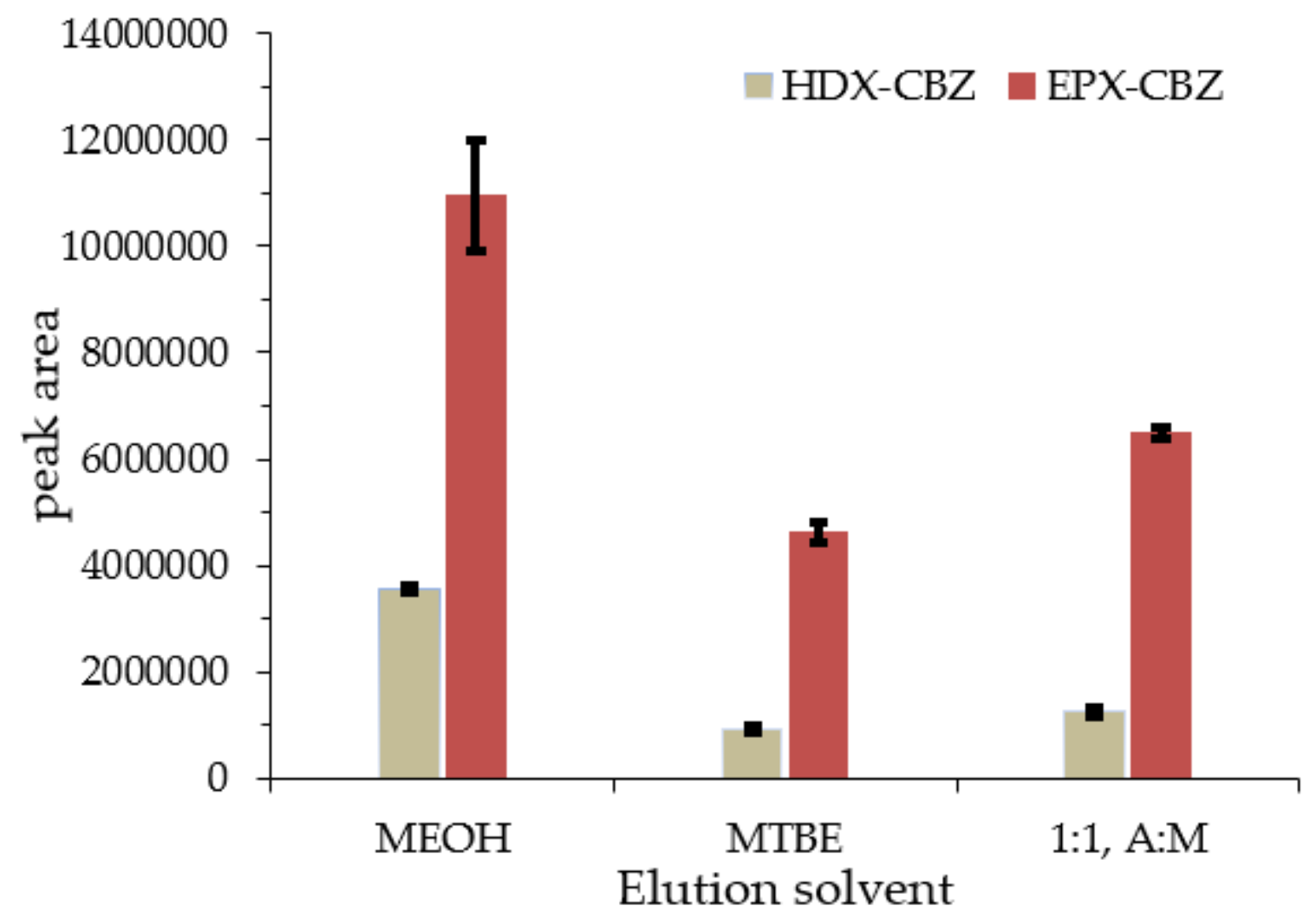

Figure 4

Effect of elution solvent on recovery of the by-products; HDX-CBZ and EPX-CBZ. 

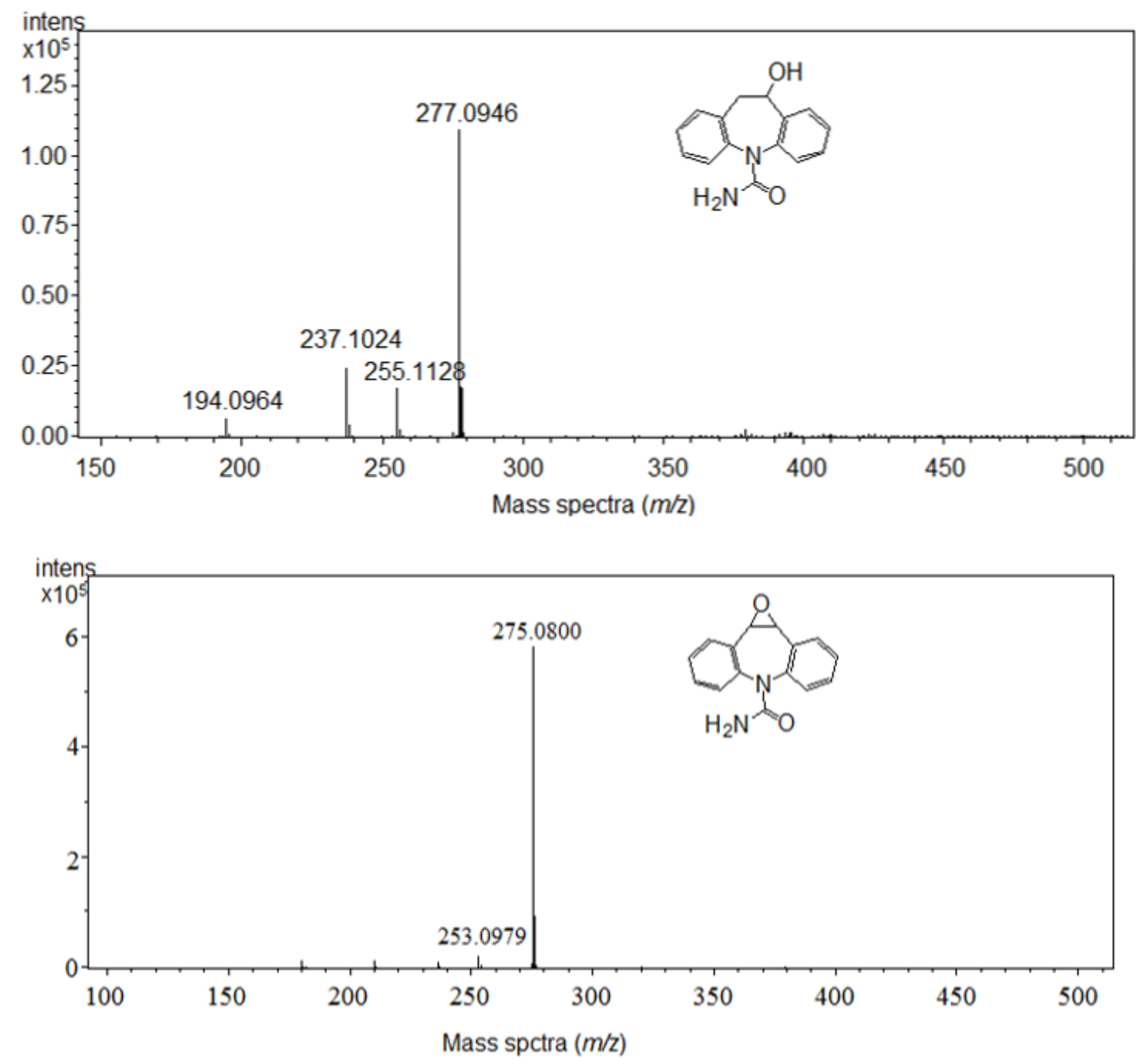

Figure 5

The profile of elucidating the by-products during the electrochemical oxidation process: (top) HDX-CBZ; (bottom) EPX-CBZ. 


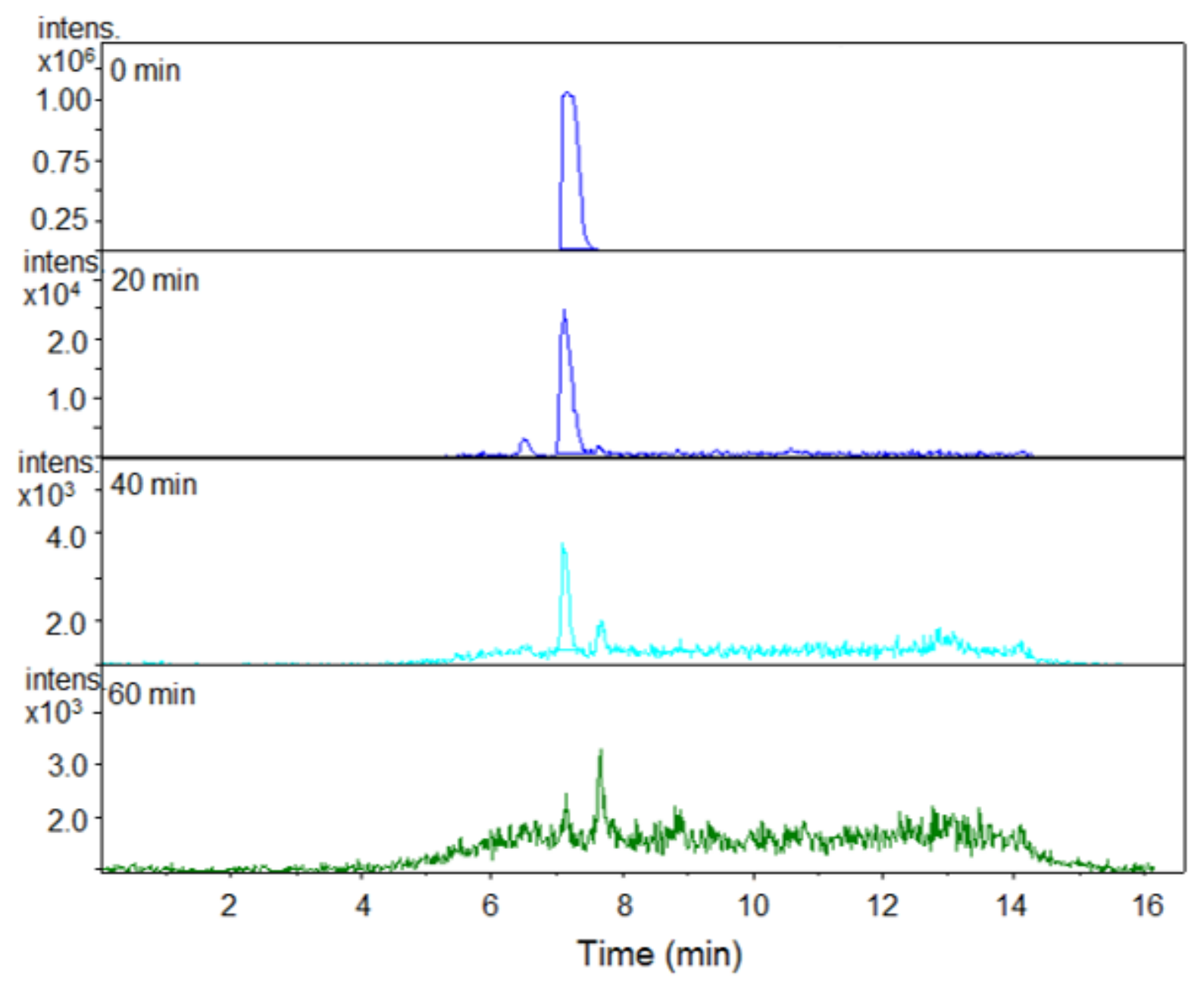

Figure 6

Liquid chromatography-time of flight/mass spectrometry chromatograms for carbamazepine under different conditions: $5 \mathrm{~V}, 0.5 \mathrm{~g} \mathrm{NaCl}$ and $0-60 \mathrm{~min}$. 


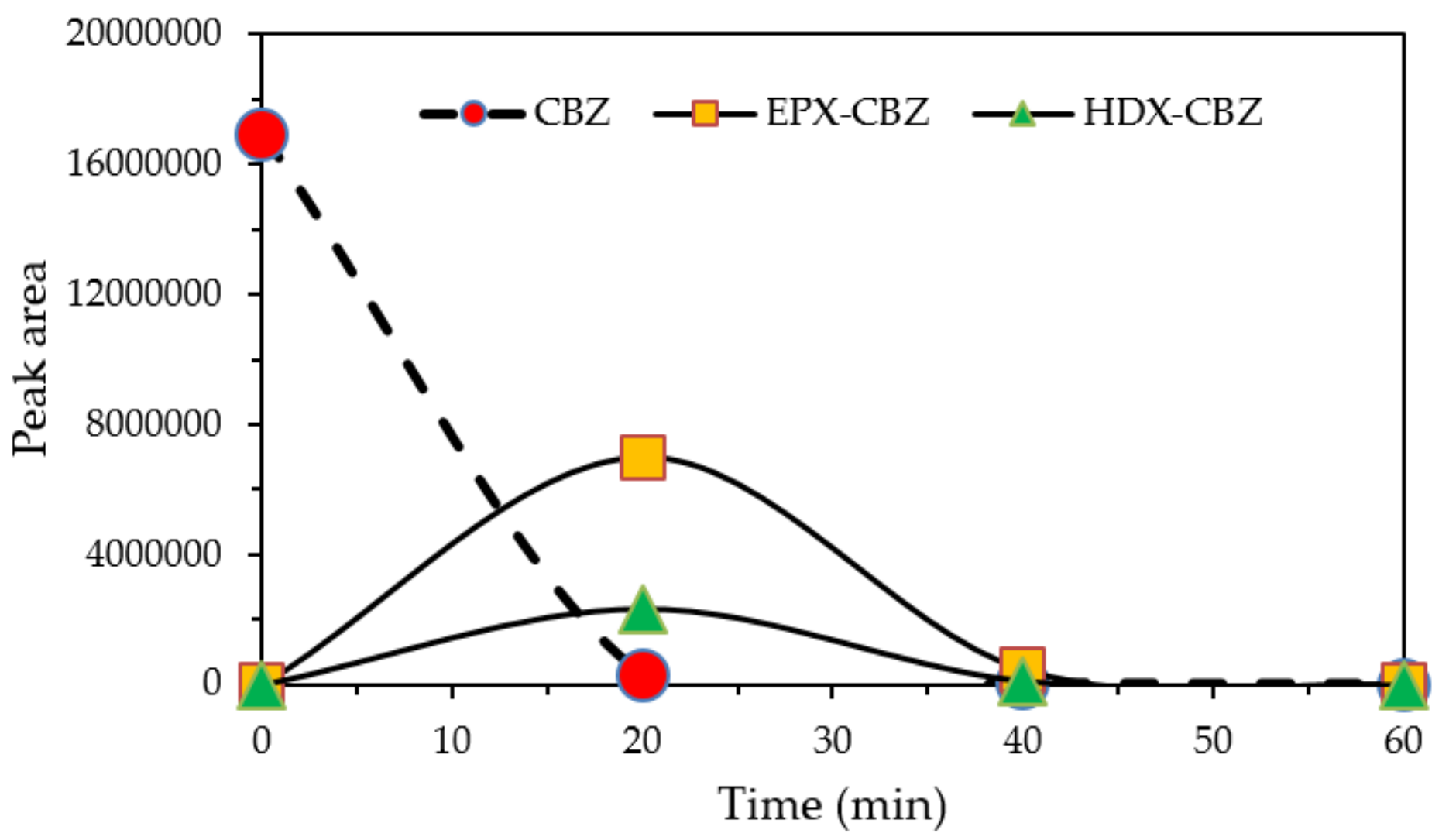

Figure 7

Monitoring of carbamazepine and both by-products (HDX-CBZ and EPX-CBZ) using LC-TOF/MS: $100 \mathrm{~mL}$ of solution, $5 \mathrm{~V}, 0.5 \mathrm{~g} \mathrm{NaCl}$. 